\title{
A Corpus-Based Analysis of Business Contract English Registers
}

\author{
Miao $\mathrm{Cao}^{1} \&$ Wei Zhao ${ }^{1}$ \\ ${ }^{1}$ School of Foreign Languages, Shandong Normal University, Jinan, Shandong, China \\ Correspondence: Miao Cao, School of Foreign Languages, Shandong Normal University, Jinan, Shandong, \\ China. E-mail: 2632719339@qq.com
}

Received: January 12, 2019 Accepted: February 10, 2019 Online Published: April 6, 2019

doi:10.5539/ijel.v9n3p158

URL: https://doi.org/10.5539/ijel.v9n3p158

\begin{abstract}
In trades between different countries, business English is the basic step and business contract is the guarantee. In this special transaction context, the wording of business contract English is fair and rigorous; the structure of it is clear; and the style of it is solemn. Based on the register theory in systemic functional linguistics, this paper analyzes the lexical, syntactic and textual rhetorical features of contract English. Some of the data are from business English Corpus established by University of International Business and Economics. It aims to promote the writing of business contract English.
\end{abstract}

Keywords: business contract English, register, field, tenor, mode

\section{Introduction}

\subsection{Importance of the Study}

Business contracts, in short, are bilateral agreements signed by two or more contracting parties for trades. It stipulates the rights and obligations of both parties. It is established according to law and protected by law. As far as the contracting parties are concerned, it is a programmatic document that guarantees transactions. Therefore, it is very important for companies to sign business contracts that possess legal effects. Nowadays, a large number of Sino-foreign business contracts have been signed in different ways with the development of economics and technologies, such as the international sales and technology transfer contract, the Sino-foreign venture contract, the foreign labor contract and the international leasing contract (Gao, 2015). Different from domestic contracts, there are huge language and cultural barriers in the contracting parties.

So far, business English and contract English have been studied a lot both in the domestic and abroad. However, the research mainly starts from two aspects. Firstly, it stems from the Skopos Theory and functional Equivlance Theory. The paper compares Chinese business contracts with English's to study the translation process and translation results, so as to achieve the elegance and faithfulness in translation. Secondly, it makes descriptive statistical analysis of business English without the discrimination of different sub-domains, such as words, tenses and modalities of business English. The studies above lack corpus-based studies and don't distinguish business contract English with other types of business English, for examples, business letters, marketing programs and business news reports. Therefore, based on the sub-corpus of business contract English, which is a part of the large-scale business English corpus established by the University of International Business and Economics, this study mainly makes a statistical analysis of the register features of business contract English, with a view describing the register features of business English more pertinently and more comprehensively.

\subsection{Register Theory}

It is not Halliday but Reid that first proposes the notion of register. At that time, it refers to text variants. Then Halliday inherited and developed the concept. In the early 1960s, he inherited and developed Malinowski's context of situation and context of culture and also borrowed from Firth's statement of "typical linguistic environment". In 1964, according to the book Linguistic Science and Language teaching, Halliday carries out a preliminary definition of register, which holds that register means the functional variety of language and different forms of language changes resulting from the change of context (Halliday, 1964). Since then, this theory has been continuously improved. In 1976, Gregory's context theory states that contextual context refers to the immediate environment of language and mainly includes three contextual variables: the field of discourse, the tenor of discourse and the mode of discourse. After that, in 1978, Halliday makes a more comprehensive definition of the register in the book Language as Social Semiotics. He holds that there are three types of 
language situations, namely, the field, the tenor and the mode, which are closely related to the three meta-functional systems of language. He elaborates the register as "the structure of meaning that is usually associated with a situation type". It is a "sense potential" and a meaning system of language (Halliday, 1978, p. 12).

The ideology of Halliday's register mainly includes three aspects. First, register is the functional variety of language. It is determined by parameters of context of situation, namely, field of discourse, mode of discourse and tenor of discourse. That is to say, in different registers, the same language will lead to different communicative effects and achieve different communicative functions. Secondly, register is the variant of language. Language is changed and the dialect is a good proof of language variants. Meanwhile, the language keeps constantly developing with the rapid development of the society. People no longer use a single language form in all occasions, and thus produce spoken and written language. Thirdly, register is described by field, tenor and mode, that is to say, describing discourse features can be expanded from the field of discourse, mode of discourse and tenor of discourse (Gao, 2015).

The understanding of the lexical, syntactic and textual features of business contract English will help both sides write standardized business contracts, so as to conduct cross-border transactions and protect their legitimate rights and others. Meanwhile, it will provide a linguistic perspective for teaching business English translation, thus promoting the development of English translation teaching.

\subsection{Researches Hypotheses}

This study answers the following questions in detail.

(1) What are the subjective words in English business contracts? And what lexical features of Business Contract English they reflect?

(2) What are the word clusters in English business contracts? And what syntactic characteristics of Business Contract English they reflect?

(3) What are the basic statistical characteristics of English business contracts? And what textual features of Business Contract English they reflect?

\section{Method}

This quantitative corpus-based study was conducted from November 2017 to March 2018 (download the articles) and from July 2015 to September 2016 on articles downloaded from the business English corpus built by the University of International Business and Economics. The corpus contains thousands of articles published in hundreds of scientific journals and is composed of several smaller databases, namely: company reports; financial news; financial law (company contract); business letters; economical academia; celebrity speeches; and government documents. First, the general word of "business contract" was searched by ticking the "Full-text" and "Peer-reviewed" tabs so that the found articles would possibly be the most relevant full-text and peer-reviewed articles in business contracts. Then in the journal section which showed the names of the journals in which the found articles had been appeared, journals based on the sub-corpus of financial law were selected. Subsequently, the articles of each journal were arranged and downloaded "most recent first". In order to reflect the originality of business contract English and not destroy the integrity of the text, this study tries to keep a balanced proportion of various texts while extracting samples. In fact, the nonprobability consecutive sampling method was used. The publication time of the corpus is in 2003 and there are 506063 words used in this study in sum.

In this paper, WordSmith Tools 5.0 is used to analyze the corpus. For the study of basic statistical features, to begin with, this paper uses the lexical analysis method to calculate the average length of the sentence and the variance of the business contract English. Then the method of descriptive statistical analysis is adopted to illustrate its specific characteristics. As to subjective words, this paper intends to use the business contract English corpus as an observational corpus and another general academic English Corpus as a reference corpus to automatically extract the top 20 positive subjective words overused in the Business Contract English Corpus. As to word clusters, this paper will make collocation analysis on the basis of the positive subject thesaurus extracted and then count out the most frequently used word clusters. Finally, its register characteristics are described by means of the lexical analysis, the thematic analysis and the collocation analysis.

\section{Results}

\subsection{Basic Statistical Information of Business Contract English}

According to the data, the average sentence length of business contracts is 31.02 , while that of ordinary 
academic texts is 23.26 ; the standard deviation of sentence length of business contracts is 32.47 , while that of ordinary academic texts is 15.6. This shows that, unlike ordinary academic texts, the length of business contracts reflects a distinct polarity: the business contracts are the combination of minimalist sentences and long-complex sentences. This difference actually comes from the stylistic features of business contract English. Short sentences are concise and direct to the subject; while the long-complex sentences in it provide the supplementary explanations. So, the use of the two kinds of sentences makes the rights and obligations of both parties clearer, make the transaction fairer and smoother.

Table 1. Comparison of basic statistical characteristics between English business contracts and general academic texts

\begin{tabular}{lll}
\hline Types of corpus & Average sentence length & The standard deviation \\
\hline English business contract & 31.02 & 32.47 \\
General academic texts & 23.26 & 15. \\
\hline
\end{tabular}

\subsection{Subjective Words and Word Clusters in the Business Contract English}

Subjective words are important manifestations of textual features. It is precisely those words frequently used or are overused that embody the register features of business contract English. Due to length limitations, Table 2 merely enumerates the top 20 positive subjective words. Through the horizontal and vertical analysis of these words, it can be calculated that technical terms, abbreviations, loanwords, archaic expressions, conjunctions and modal verbs are widely used in business contract English.

Table 2. Statistics of word clusters in English business contracts

\begin{tabular}{lll}
\hline & frequency & Examples \\
\hline three-word clusters & 516 & use and wont; seller and buyer; the expense will; lose and damage \\
four-word clusters & 330 & later in this contract; less than container load; in the case of \\
five-word clusters & 107 & the date of the meeting; the expense of the goods; the buyer shall be entitled \\
six-word clusters & 59 & between the contractor and the distribute \\
seven-word clusters & 31 & misunderstanding to any other price or expense \\
eight-word clusters & 24 & in writing between the seller and the customer \\
\hline
\end{tabular}

According to Table 2, the most frequently used ones are three-word clusters, most of which come from high-frequency subjective words. Business contract English belongs to the contractual style that strives to be accurate and unambiguous. Therefore, the three-word clusters of synonyms are commonly used to clarify concepts and avoid possible misunderstandings and disputes. These kinds of three-word clusters are usually linked by conjunctions, for example, conjunction "and" and conjunction "or" are often used in these structures. For instance, "terms and conditions" are translated directly into money plus requirements. However, they can be separated, terms refer to the price of goods or the cost of services, while condition refers to terms or prerequisites. There are still many such fixed collocation patterns that use conjunction "and" and conjunction "or" to connect synonyms or synonyms in business contract English. Such as force and effect = takes effect; use and wont = habits, practices and so on. The use of this special structure effectively avoids misunderstandings and disputes caused by polysemy, which characterizes business contract English with solemn structure and rigorous wording. 
Table 3. The top 20 subjective words in English business contracts

\begin{tabular}{llllllll}
\hline $\mathrm{R}$ & Key Word & Freq & $\%$ & RC.Freq. & RC\% & Keyness & P value \\
\hline 1 & THE & 538 & 1.79 & 129 & 0.07 & 1391.13 & 0.0000 \\
2 & ANY & 359 & 1.20 & 3 & - & 1279.06 & 0.0000 \\
3 & BUYER & 857 & 2.87 & 774 & 0.47 & 1220.85 & 0.0000 \\
4 & GOODS & 276 & 0.90 & 0 & - & 1027.96 & 0.0000 \\
5 & OR & 246 & 0.81 & 4 & - & 885.27 & 0.0000 \\
6 & SHALL & 205 & 0.68 & 7 & - & 704.65 & 0.0000 \\
7 & CONTRACT & 203 & 0.67 & 28 & 0.01 & 589.39 & 0.0000 \\
8 & BY & 2817 & 9.49 & 9730 & 5.61 & 471.54 & 0.0000 \\
9 & DATE & 128 & 0.41 & 1 & - & 470.46 & 0.0000 \\
10 & MEETING & 109 & 0.34 & 0 & - & 404.65 & 0.0000 \\
11 & CUSTOMER & 124 & 0.42 & 11 & - & 389.21 & 0.0000 \\
12 & MUST & 217 & 0.71 & 136 & 0.08 & 371.23 & 0.0000 \\
13 & WILL & 85 & 0.26 & 1 & - & 305.91 & 0.0000 \\
14 & DELIVERY & 82 & 0.24 & 1 & - & 300.17 & 0.0000 \\
15 & AGREEMENT & 82 & 0.24 & 1 & - & 289.65 & 0.0000 \\
16 & CONTRACTOR & 98 & 0.31 & 3 & - & 280.97 & 0.0000 \\
17 & DISTRIBUTOR & 72 & 0.23 & 0 & - & 277.87 & 0.0000 \\
18 & SELLER & 81 & 0.25 & 16 & - & 229.49 & 0.0000 \\
19 & PARTY & 62 & 0.19 & 2 & - & 217.55 & 0.0000 \\
20 & EXPENSE & 393 & 1.32 & 851 & 0.52 & 213.02 & 0.0000 \\
\hline
\end{tabular}

\section{Discussion}

\subsection{Lexical Rhetorical Features of Business Contract English}

In Halliday's opinion, field refers to the thing and the social actions that are happening; what activity that participants are engaged in; and in the activity language serves as an important part (Halliday, 1985). The field of discourse refers to the scope of actual events involved in speech activities, including the type of the conversation, the external experience of the speaker, and the psychological experience of both sides. In the process of speech activity, in order to achieve communicative purposes, the speaker should choose appropriate language expression within this range. Beyond this field or scope, the meaning will become incomprehensible or even ambiguous. Business Contract English belongs to business English and it is also one of the subfields of English for special purposes. In this kind of discourse, almost all the genres involved are related to business negotiation, business cooperation, and legal rights and obligations of both sides. In such context, business contract English pursues rigorous and standardized wording, solemn and elegant structure, and unambitious meaning. In all, it cannot cause trouble to both transaction sides. Therefore, in order to guarantee the authority of business contracts, more precise, standardized and accurate words such as technical terms, archaic words, abbreviations and loanwords are frequently used.

\subsubsection{The Use of Technical Terms}

In order to show a distinct image of rights and obligations of both parties and penalties for the violation of the convention, business contract English often used legal English to ensure the authority of the contract and the seriousness of the convention. Legal English is more formal than the ordinary written language. Generally speaking, common words in legal English are neutral ones without emotional color and prejudice. Meanings of these neutral words are single, clear and will not cause ambiguity. Common legal terms used in business contract English are as follows, such as advance payment, infringement and financial responsibility.

\subsubsection{The Use of Abbreviations}

Legal English is precise in wording, and strives to make sentences without ambiguity and loopholes. These characteristics are also reflected in business contract English. At the same time, in order to guarantee the unity of the sentence meaning, many supplementary explanations should be used inevitably. Every coin has two sides. Although these supplementary explanations can guarantee the authority of business contract English, they are not conducive to international business communication and the preservation and recording of relevant contract documents. The use of acronyms can overcome this shortcoming. In order to avoid redundant sentences, many conventional parts of business contracts usually appear in the form of abbreviations. For example, $\mathrm{LC}=$ letter of credit; $\mathrm{FOB}=$ Free on Board; $\mathrm{A} / \mathrm{R}=$ all risks. These words are clear in meaning and concise in structure. They have been used as conventions in the world and will not cause ambiguity. It is worth noting that not all words 
can be abbreviated. Only the payment method, the delivery method and the insurance method, which have been recognized and will not cause ambiguity, can be simplified to abbreviations. Other information such as places, names and dates, cannot be abbreviated.

\subsubsection{The Use of Loanwords}

Cognitive metaphors are instantiations of cultural categories manifested in the language spoken by the community that shares a common set of characteristics within a given cultural matrix (Crina \& Teodora, 2013). Business contract English is a sub-field of ESP, which means that its language is bound to be influenced by other languages like English. This is due to historical factors. English stems from Latin, so lots of business contracts terms can also be seen in Latin. For example, as per (according to) and stare decisis (following precedents) are the products of Latin cultural influence. One of the influences of the French Revolution on the rest of the world is embodied in legal English. Nowadays, many legal English used in business contract English comes from French. For example, complain means "complaint" in the context of academic communication, while complaint means "complaint" in the legal text.

\subsubsection{The Use of Archaic Words}

Many concise archaic words are widely used in business contract English in order to give consideration to the simplicity, accuracy and conciseness of language. These archaic words are usually composed of here, there, where plus in, on, to. These words have a single meaning and a concise structure, which not only accurately express the meaning, but also effectively prevent the sentence pattern from being too long or too complicated, thus not conducive to international business communication and text preservation. Commonly used archaic languages are hereby $=$ by means of this; hereinafter $=$ later in this contract; thereinafter $=$ later in the same contract and so on.

\subsection{Syntactic Rhetorical Features of Business Contract English Under the Mode of Discourse}

According to Halliday, the mode, a symbolic organization, refers to what the role of language; what participants expect to do in the context by using language. It's the symbolic organization of discourse, the status of discourse and language function in the context, including channels (whether spoken or written form, or a mixture of the two) and rhetorical methods (Halliday \& Hasan, 1985). So, the mode of discourse refers to the relationship between communicators. It includes two aspects: first, social roles, social roles have many manifestations such as teachers, students, colleagues, employees, bosses, etc. Second, communicative roles, it only involves two manifestations, namely, giving and taking. People may have multiple social roles at the same time, but can only play one communicative role once a time. In business contract English, its communicative purpose and communicative roles should be achieved by different potential meanings. In order to ensure the fairness of business contracts, the sentences of business contracts should be neutral and free from any emotional colors. The passive sentence reflects this point perfectly. At the same time, one of the existing necessities of business contracts is to make the rights and obligations of both parties reasonable. The expression of rights and obligations is usually expressed by modal verbs to define what must be done, what is permitted to do and what is prohibited to do. In conclusion, in order to guarantee the authority of business contracts, neutral terms such as modal verbs and passive voices are often used.

It is worth noting that modal verbs in business contract English differ from that in academic terms. Nelson (2006) also claims that not only do words in the business environment have semantic prosodies, that is, they are found to regularly collocate with word groups that share semantic similarity, they also have prosodies that are unique to business, separate from the prosodies they generate in the 'general English' environment. Shall means the terms in the contract, if breached, people would be punished. May means the rights in the contract. Should is hypothetical. Must and will both express the obligations to be undertaken, the difference is that whether there exists a legal enforcement. The use of these modal verbs effectively reflects the percentage of responsibilities and obligations in the contract and brings many conveniences to business cooperation. That is, through these modal verbs, both transaction parties quickly distinguish the boundary of rights: what can be done, what cannot be done, what can be done under certain conditions, and what will become prohibition without these conditions.

\subsection{The Textual Rhetorical Features of Business Contract English Under the Tenor of Discourse}

Tenor refers to "participants of the process as well as the nature, status and roles of them; what kinds of role relationship obtained among the participants and whether the relationship is permanent or temporary; the speech roles that they are showed in the conversation and the social relationship where they are involved" (Halliday, 1985). The tenor of discourse refers to the medium and channel of communication, which includes rhetorical devices. Business contract English belongs to official documents. In the textual structure, every business contract 
is like a letter. It has a strict and complete structure system, which includes three parts: preface of a treaty, body of a treaty and end of a treaty. The elements contained in each part are relatively fixed. The replenishment and revision of the business contract must be within this framework. Otherwise it will be a business contract without legal effects and legal protection. At the same time, business contracts belong to formal written texts, thus it certainly contains many basic elements of cohesion and coherence in a text.

\section{Conclusion}

To sum up, business contract English, as a kind of conventional document, is fair and rigorous in wording, clear and concise in structure and solemn in style. Through the analysis of business contracts, it can be found that business contract English mostly uses fair and rigorous terms such as technical terms, archaic words, abbreviations, loanwords to reflect its characteristics of word selection; in terms of syntax, neutral terms such as modal verbs and passive voice are used to express its solemn style. In terms of discourse level, the structure of business contracts is strict and often standardized. It belongs to the formal written style. Business English language as a genre in itself has been widely analyzed and debated in specialist literature, as extensive research has been carried out in the field of teaching English for Specific Purposes. The formality of English Business Contracts is not external to the substance of business interactions, but a way of articulating, facilitating and simplifying the complexity of business interactions (Stefanos \& David, 2012). Meanwhile, a clear focus on the register features of Business Contract English will help teachers and specialists to find more methods to teach students how to use the business language correctly and appropriately.

\section{References}

Cheng, W., \& Ho, J. (2017). A corpus study of bank financial analyst reports: sematic fields and metaphors. International Journal of Business Communication, 54(3), 258-282. https://doi.org/10.1177/232949941552790

Crina, H., \& Teodora, P. (2013). Developing Business Students' Linguistic and Intercultural Competence through the Understanding of Business Metaphors. Procedia - Social and Behavioral Sciences, 10(93), 1080-1084. https://doi.org/10.1016/j.sbspro.2013.09.334

Halliday, M. A. K. (1978). Language as Social Semiotic: The Social Interpretation of Language and Meaning. Edward Arnold.

Halliday, M. A. K. (1985). An Introduction to Functional Grammar. London, Arnold.

Halliday, M. A. K., \& Ruqaiya, H. (1985). Language, Context and Text: Aspects of Language in Social-Semooitic Perspective. Geelong, Vic: Deakin University Press.

Halliday, M. A. K. et al. (1964). The Linguistic Sciences and Language Teaching. Modern Language Review, 62(1), 106.

Hu, C.-Y. (2015). Corpus stylistics approaches to the characteristics of English for business contracts. Journal of PLA University of Foreign Languages, 9, 10-19.

Gao, S.-W., \& He, W. (2015). Register thought evolution in SFL. Foreign language Teaching and Research, 3, $48-54$.

Mike, N. (2006). Semantic associations in Business English: A corpus-based analysis. English for Specific Purposes, 25(2), 217-234. https://doi.org/10.1016/j.esp.2005.02.008

Nelson, M. (2000). A Corpus-based Study of Business English and Business English Teaching Materials. Unpublished Ph. D. Thesis, University of Manchester.

Stefanos, M., \& David, F. (2012). Contracts as a facilitator of resource evolution. Journal of Business Research, 9(65), 1251-1253. https://doi.org/10.1016/j.jbusres.2011.11.002

\section{Copyrights}

Copyright for this article is retained by the author, with first publication rights granted to the journal.

This is an open-access article distributed under the terms and conditions of the Creative Commons Attribution license (http://creativecommons.org/licenses/by/4.0/). 